\title{
Reference Work with Periodicals: Recent Progress and Future Needs
}

\section{Louis Kaplan is reference librarian of the University of Wisconsin Library.}

SAVE THE magazines-let the books $\mathcal{S}$ burn!"1 a librarian wrote some ten years ago. Today, on all sides there is an increasing realization of the importance of periodicals. New studies and investigations are being conducted, and new indexes are being compiled. For the first time, a number of library schools are offering a separate course on periodicals.

These recent developments, in so far as they relate to the reference use of periodicals, are summarized in this article. In addition, a number of suggestions are offered with respect to future needs.

\section{Indexes and Abstracts}

With regard to existing composite indexing and abstracting services there are three main difficulties: incomplete coverage, duplication of titles, and the time lag between the publication of periodicals and the appearance of the indexes. These problems are now the subject of study by a committee of the Serials Section of the American Library Association. At a later date the committee intends to examine the question of the promptness with which new titles are admitted to the indexes. In this connection an excellent suggestion has been made by Henry Black, technical con-

1 Munn, Ralph. "Library Mission of Magazines." Wilson Bulletin 4:59, Oct. 1929. sultant for the Commonwealth College library:

The selection of periodicals to be indexed or covered by abstracting services is of serious interest not merely to libraries but to all organizations concerned with education, research, industry and government. It is our belief that selection can be handled satisfactorily only by a prominent body such as that proposed by the A.L.A. committee. However, to limit the group to librarians, as suggested by that committee, would be a mistake; for the problem is essentially a social one, and a representation should be required of all the various interests-library administrators and trustees, reference and research workers, scientific societies, special libraries, indexing and abstracting agencies, periodical publishers, and the main economic and political points of view. ${ }^{2}$

In addition to the work of the Serials Section committee there are a number of other encouraging signs of activity. The H. W. Wilson Company is preparing a revised edition of Poole's Index. In this edition the two main weaknesses of the index will be corrected : there will be (I) a systematic scheme for subject headings and (2) author entries.

At New York University a Work Projects Administration project is engaged in compiling an index to early American periodicals. When completed it will include 339 titles ( 7000 volumes) of which only a few are duplicated in Poole's Index. The years to be covered are from $\mathbf{I} 728$ to

\footnotetext{
${ }^{2}$ Library Quarterly, 10:62, Jan. 1940.
} 
1870. This valuable index should be published. If this is impossible, a number of libraries will undoubtedly wish to have it microfilmed.

Another very useful tool is being prepared at the University of California under the direction of Barbara Cowles. This is a subject index to the Union List of Serials. Two other studies are under way at the same school: an analysis of abstracting services treating of endocrine literature, and a comparison of the titles included in Ayer's, Willing's and Sperling's directories with those in the major indexing services. At the University of Michigan an analysis of the Agricultural Index and the Experiment Station Record is being made. At the University of $W$ isconsin, under the direction of the writer, a subject analysis of the titles in the Bibliographie der fremdsprachigen $Z$ eitschriftenliteratur will soon begin.

\section{No Satisfactory Index to Book Reviews}

From the viewpoint of the general college and university library there is as yet no satisfactory index to book reviews. The Book Review Digest omits many books which are of interest to the larger libraries, and records only those reviews which appear immediately after the publication of a book. These two weaknesses are corrected in the Bibliographie der Rezensionen. Unfortunately, this publication is not issued promptly enough to be of use in locating reviews of recent books, and its arrangement is far too intricate for most library patrons. A third index, the Technical Book Review Index, cites reviews exclusively from technical periodicals and is therefore of limited use in general reference work.

It is doubtful if an American publisher could be interested in providing a new index to reviews which would satisfy the needs of larger libraries. Some time ago the writer had a brief conversation with Mr. H. W. Wilson who was skeptical as to the financial success of such a venture. A second and perhaps more feasible approach to the problem would be for American and English librarians to request the publisher of the Bibliographie der Rezensionen to speed up its publication and make its use less difficult.

Another important need is for an up-todate check list of all periodicals which have ever been indexed. Ulrich's Periodicals Directory, it is true, provides a clue to those being currently indexed. It does not, however, show in what year the indexing of each periodical was begun, nor does it include discontinued periodicals. To meet this need the writer has sponsored a W.P.A. project which is expected to start this summer. If possible, this check list will be made available to other librarians.

A much larger and more important undertaking relates to the fact that the indexes are now so great in number and cover so many years that there is a growing need for an index to the indexes. This phrase "index to indexes" is not to be taken literally. What is meant is that many periodicals contain, in addition to articles and book reviews, a great amount of special reference material which, though indexed, is now very difficult to find. Examples of such materials are the dictionary of nineteenth century American authors in Blackwood's Magazine (182425), the periodic compilations in Editorial Research Reports showing for a Congressional session how each Congressman voted on important issues, and the list in the Bulletin of the National Research Council of private industrial research laboratories 
in the United States. For such items, and for similar items which are unindexed, there is needed a single-volume guide.

In this proposed project the periodicals would be alphabetically arranged and for each periodical there would be a list of its special reference features. A subject index would follow the alphabetical list. With such an arrangement, the publication could be used as a selection aid as well as a reference guide. Unfortunately, it is beyond the powers of a single person to compile a work of such great magnitude. The writer has made a start on periodicals in the field of history. ${ }^{3}$

\section{Selection Aids}

A variety of methods has been employed in compiling aids for the selection of periodicals. One fairly satisfactory method is to pool the opinions of a large number of subject specialists and librarians. This was the procedure followed in Lyle's Classified List of Periodicals for the College Library, and in Shaw's List of Books for College Libraries. This method is superior to a selection based purely on the opinions of experts, as was done in Fox's Selection of a Basic List of Periodicals for a Teacher's College Library (thesis, University of California, I930), and to a selection limited to the opinions of librarians, as was done in Copeland's "Checklist for a Teacher's College Library" (Peabody Journal of Education, July 1934).

Any selection, however, which is based on personal opinions must be regarded with some suspicion. For this reason the statistical method, first employed for chemistry periodicals by Gross (Science, October 28, 1929), was a definite step forward.

${ }^{3}$ A fuller description of this project will shortly appear in the Wilson Library Bulletin.
Gross' procedure was to choose a basic periodical and compute from this the footnote references to other periodicals. With this method it is possible to show somewhat conclusively which periodicals will be wanted by scholars. The chief weakness of the procedure is that the final results depend upon the choice of the basic periodical or periodicals. Nevertheless, the method has attracted considerable attention; similar studies have been made for periodicals in electrical engineering, civil engineering, geology, mathematics, agriculture, and medicine. It is to be hoped that further investigations will be conducted.

With respect to the selection of newly published periodicals, there is an especially difficult problem since statistical evidence of their usefulness is lacking. Nor is the problem solved simply by waiting until a periodical is taken up in a composite index. If a periodical contains material of a distinctive nature, it should be purchased immediately-whether indexed or not. Even though unindexed, a periodical can be put to extensive use. Another reason for prompt purchase is that after a few years early numbers of a periodical are almost impossible to obtain.

New periodicals are frequently described in the older periodicals. The description, however, is usually too brief to be of service in selection. Furthermore, it is a tremendous task to keep up with new periodicals in this manner. For these reasons it would be very helpful if journals like College and Research Libraries and Library Quarterly would publish compact reviews of important new periodicals. These reviews should be written by subject specialists. They should appear soon after a few numbers of a new periodical have been published. 


\section{Interlibrary Loans and Microfilming}

Two difficulties present themselves with respect to the interlibrary loan of periodicals. One is the cost of transporting a heavy volume in which only a single article is to be used and the second is the reluctance of librarians to lend materials which are frequently called for by their own patrons. Connected with this situation is the inevitable fact that as regional schemes of cooperation develop, more and more borrowing will become necessary.

The only solution, barring unforeseen developments, is the increasing use of microfilm. Before this can be really effective, a greater number of libraries must be equipped with the apparatus essential to the filming of materials. This is mainly a problem for larger libraries since they are most frequently called upon for loans. Fortunately, definite progress is being made. A recent investigation disclosed that of 57 libraries questioned, 34 were already prepared to film their materials and 2 more were about to institute the service. A number of large libraries, however, have as yet done nothing along this line. ${ }^{4}$

On the other hand, few of the smaller libraries have been equipped with reading machines. This is an essential step since it is from these libraries that a majority of the requests come for interlibrary loans. There is really no good reason why this step should be delayed. A serviceable reading machine can now be purchased for seventy-five dollars. Because of the money saved in transportation of heavy volumes, this machine will soon pay for itself. Furthermore, in this way a library can make available to its patrons much material

\footnotetext{
4 Brown, Harold P. "Survey of Microfilm Sources." Journal of Documentary Reproduction 2:120-22, June 1939 .
}

which would otherwise be impossible to borrow.

In this same connection it is important to note that through Bibliofilm it is now possible to purchase on film entire sets of important periodicals. The cost of this service, if over ten volumes are wanted, is one-half cent per page.

\section{Need for First-Hand Knowledge of Periodicals}

It is unfortunately true that the majority of reference workers do not possess a first-hand knowledge of periodicals. Instead, there is an almost exclusive reliance upon the indexing services. This is a deplorable situation because it means that much reference material goes to waste.

The truth is that it is not even possible to use the indexes efficiently without intimate knowledge of the periodicals. Suppose, for instance, that a patron wishes examples of cartoons relating to the European war of $1914-18$, and that the books containing this material are not available. Now it so happens that an excellent collection of these cartoons can be found in Current History, and these, of course, are indexed in the Readers' Guide. But if it does not occur to the reference worker that cartoons are contained in periodicals, will he make use of the composite indexes?

Suppose again that a college freshman is seeking a review of a history book. Through the Book Review Digest it is possible that he will find references to such periodicals as the American Historical Review, Nation, Current History, and the English Historical Review. Here the patron may well be advised as to which of these periodicals are too technical for his educational background. In other words, the librarian must be fully acquainted 
with each of the periodicals, if he is to be of service to the patron.

Another good reason for not relying exclusively upon the indexes is that many important periodicals are as yet unindexed. Of course, the reference department cannot possibly maintain a comprehensive indexing of its own. Nevertheless, it is frequently possible to put a periodical to use simply by knowing its general nature. Thus, it is natural to presume that material on Mexican mosaics will be found in the periodical Mexican Art and Life. In effect, an unindexed periodical can be expected to contain certain material and be referred to in the same manner as an encyclopedia.

Besides being acquainted with the general nature of an unindexed periodical, a reference librarian will find it very useful to keep a record of any unusual reference items which it may contain. An example is the Standard Rate and Data Service, one of the few sources which reveals how many copies of a certain periodical are sold in a particular state. If a record of such items were kept on file in the reference department, as is done in some libraries, it would soon prove its worth.

For these reasons there is a very real need for reference workers to go beyond the indexes and to get into the periodicals themselves. There is no royal road to a knowledge of periodicals. They must be studied systematically and at great length. In addition, books about periodicals must be read, such as Mott's History of American Magazines, and Graham's English Literary Periodicals.

There is a pressing need for more adequate professional instruction in reference work with periodicals. This is not meant as a reflection upon reference teachers. Instead, it is intended to emphasize the fact that when reference books and reference periodicals are taught in combination, the latter suffer. In most instances, only a small percentage of the time is given to periodicals. Furthermore, the instruction rarely consists of more than a discussion of the periodical indexes. The periodicals themselves are usually ignored. This is an unfortunate situation, for without a first-hand knowledge of the periodicals, efficient reference work is impossible.

The proper solution, it seems, is to offer a separate course on reference work with periodicals. It could be given with greatest profit in the second semester of the first year's work. It should be offered as an elective to students who are especially interested in reference work.

Many library school directors will undoubtedly feel that there is no room for further special courses in the first year's curriculum. However, such a course could very well replace some now being offered. An example is the half year's instruction given at some schools on subject bibliographies. Bibliographies, of course, are very important, but their proper use is simply a matter of technique. It is not necessary to know all existing bibliographies. It is more important to know how to find them, and this can be, and is, taught in the reference course.

Perhaps the reader feels that an undue emphasis is here being placed on the reference value of periodicals. Nevertheless, let it be kept in mind that most libraries expend, exclusive of binding costs, at least 40 per cent of their book budget for periodicals. Thus, if libraries are to obtain a good return on their investment, periodicals must be put to the fullest possible use. Is this not reason enough to train students more adequately in the reference use of periodicals? 